\title{
Level of customer satisfaction on small online food businesses opened during the pandemic in south of Metro Manila: Basis for enhancements for small online food \\ businesses
}

\author{
Velasco, Justin Kyle D \\ Manila Tytana Colleges, Philippines (jvelasco_05@mtc.edu.ph) \\ Tatoy, Andre A. \\ Manila Tytana Colleges, Philippines (Tatoyandre1590@gmail.com) \\ Dela Cruz, Charmae L. \\ Manila Tytana Colleges, Philippines \\ Monzon-Po, Sarah \\ Manila Tytana Colleges, Philippines
}

Received: 10 July 2021

Available Online: 1 October 2021

Revised: 23 August 2021 DOI: $10.5861 / \mathrm{ijrsm} .2021 . \mathrm{m} 7728$

Accepted: 28 September 2021

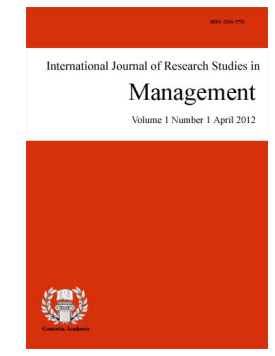

ISSN: $2243-7770$ Online ISSN: 2243-7789

OPEN ACCESS

\section{Abstract}

This study is in response of the current global pandemic situation that is affecting the hotel and restaurant industry. The jobs of the people are heavily affected because of this pandemic as the government, as well as other foreign countries, to follow social distancing and to coordinate well with the national lockdown. Since the lockdown demands social distancing many people who have been laid off or are unemployed planned on opening their own small online food business to keep a stable income during this time. Not only that but at this point many people are now following the new normal which is "Online". Every store nowadays is now setting up their virtual version of their store in order to still reach out from their customers. But the question is are people satisfied or ready for the new normal. The study utilized a mixed method of quantitative, qualitative design, and descriptive data collection and analysis. The participants of the study are people who have purchased at least 2 orders or more in the selected online food business in the past 12 months. The study includes at least a total of 75 respondents. These were divided into 25 respondents per small online food business. The results of the data gathered of the study showed that the customers/respondents were highly satisfied with the overall price, quality, and service of the selected small online food business they purchased from. Considering the fact, they mention their problems encountered. The respondents still gave a positive feedback about the overall performance of the selected small online food business, from price, quality, and service. The problems they have encountered mentions the following: delivery fee, delivery time, quality of food products after being delivered, seller is late to reply, no delivery option available only for pickup, the hassle to order online, products are not available, and wrong orders receive. The output of the study is an Action Plan for the Improvement of Small Online Food Businesses.

Keywords: new normal, online, pandemic, small online food business 


\section{Level of customer satisfaction on small online food businesses opened during the pandemic in south of Metro Manila: Basis for enhancements for small online food businesses}

\section{Introduction}

Today, online business has been recognized by the people as a reliable source of purchasing, browsing, and even starting their own business. But there are people who have experienced a negative approach to it and people who are still skeptic about the trend. Having a standard for online business in the country will help people rely on it without consuming too much of their time going outside and will also help existing businesses be recognized by the people positively. Nowadays, online businesses' rose to fame when shopping software applications were released through the people's mobile phones. Not only that, but even restaurants nationwide have been offering online deliveries including online transactions. These businesses' goal is to bring their products to their valued customer's' comfort homes without having to travel.

The consumer's satisfaction on selected small online food businesses will determine the reputation and the major standing of online business. Factors have been identified that price, quality, service determines customer's satisfaction. Price is an utmost importance in every business as it personifies yet defines what kind of business that is. According to Hanaysha (2016), Price has widely been accepted as an important marketing factor that influences consumer behavior. While brands put high efforts to exploit their business profits typically based on the price of their product or services, consumers tend to search for the best priced products and services which would deliver maximum values for them. Quality has always been a factor for pricing as it evaluates the worth of an object. In the food business industry quality is both determined by the maker and the consumer. According to Kannan. (2017). Food quality is by all accounts acknowledged as a central part to fulfil restaurant customers; be that as it may, it has been regularly ignored in restaurant benefit quality and satisfaction contemplates. Last variable is determined as service which evaluates the convenience of the customer's experience towards the online food business. According to Tomacruz and Flor. (2018) Food delivery in the Philippines is considered a major alternative to dining out and preparing meals at home for families who want a respite from home-cooked meals and cannot endure the inconveniences of dining out. Recent developments have contributed to this phenomenon.

Due to the pandemic crisis that is currently happening, small online food businesses have become a huge trend because of the convenience it provides towards consumers. Because of the social distancing protocol that the world is practicing many small online food businesses have opened because it would help them receive extra income as well as to make a name for their business to be known when the pandemic has ended. According to Sanchez (2020). She found out by $2017,64.41 \%$ of the population are using the internet. By 2018, it increased to $67.93 \%$. By 2019, it increased to $70.65 \%$. And as of July 2020, it increased to $72.7 \%$. She estimated that by 2025 , $77.14 \%$ of the population are now connected to the internet. She also conducted a survey in cooperation with Rakuten Insight which includes 16,436 respondents which tells the "Frequency of Ordering Food from Food Delivery Apps in the Philippines" as of June 2020. They found out that $23 \%$ of the respondents' order food from delivery apps once or twice a week. In comparison, with $3 \%$ of the respondents ordered at least once a day.

Due to the trends of Small Online Food Businesses and personal experiences of the researchers in ordering online food products they thought of making a research that tackles the satisfaction it produces to consumers. Based on the personal experiences of the researchers many of the problems that they encountered are based on these variables from price, quality, and service. Although, customers purchasing products from these small online food businesses have been very convenient for them since it helps them purchase products without the need to make them at their homes considering the pandemic crisis situation. 
These are the experiences that the researchers have encountered during the completion of this study based on the variables named as price, quality, and service. In terms of price, there is a lot of the same product but different prices. But also, the researchers chose the amount of food whether the product is expensive as long as it is in the budget. After the researchers have tasted the food that's how they know if it is worth the price. But sometimes it is not worth it because what the consumers see in the picture is different from the actual product itself. In terms of quality, the product quality has different variety of problems that may be encountered in small online food businesses which have an unpleasant taste where in the company added a different flavor that the customers are not familiar with, foul odor coming from the product and different appearance from the original product. In terms of service, the products offered are convenient in a way that the products offered are worth the purchase instead of making it at home. But due to the complications of being online, contacting the business owners is rather timely and with that it takes time for customers to know any updates about their purchase orders. In terms of food safety packaging, these selected small online food businesses are using well packaged products.

The researchers chose to conduct this research to have a basis in formulating an action plan in improving small online food business on the perception of the customer. This study defines the importance and convenience of small online food businesses that helps people recognize that no matter the situation the person is experiencing; the small online food business is always there to cooperate on the basic food needs of every consumer. The findings of this study could contribute to the level of customer satisfaction on small online food businesses which gives the businesses an insight on how the consumers is satisfied.

\subsection{Objective of the Study}

This study aims to determine the Level of Customer Satisfaction on Small Online Food Businesses Opened during the pandemic in South of Metro Manila. This will serve as an action plan for small online food businesses. Determine the levels of customer satisfaction of the respondents in a small online food business in terms of Price, Quality and Service; Determine the problems encountered and recommendations in ordering from a small online food business; and lastly, proposed an action plan based from the result of the study.

\section{Methods}

Research Design - The research design used in this study are Qualitative and Quantitative research. The mixed method design in this study will identify the problems encountered by the respondents in terms of small online food business in the pandemic. Mix method was used by the researchers to strengthen the findings of the study that binds itself to the statement of the problem shown that would be best fit to solve the problem and to get a better point of view of the respondents. The researchers gave out surveys to the customers of the small online food businesses qualitative referees to the questions that in line with our variables of price, quality and service. For qualitative this is where the questionnaire asks for feedback about the small online food businesses.

Sample and Sampling Technique - In this study, the researchers used the purposive sampling technique. The respondents focused on those who are customers of small online food businesses. The online survey questionnaire was used by the customers in order to pinpoint the problems on price, quality, and service to know the levels of the customers' satisfaction. The study includes a total of (75) respondents who are divided into 3 for each small online food business. Each business will have 25 respondents that have ordered multiple times from the small online food business. The researchers had selected those 3 small online food businesses that are in south of Metro Manila based upon their products that are baked goods. Considering that they offer the same product the researchers will now dwell into the price, food quality and service of the small online food business.

Purposive sampling technique was used in the study or also known as selective sampling technique. It is a type of a non-probability sampling technique that is based on the population's characteristics and the studies objectives. The researchers will propose an action plan that will measure the customers' satisfaction towards small online food businesses. The specific criteria of the respondents are gender, age and the respondents have 
order twice in the selected small online food businesses. The researchers determine the respondents by looking into the record of the business to see who are the respondents that have ordered twice in their business.

Research Instrument and Technique - The data gathering method that the researchers will be using is an online survey questionnaire that is self-made and will be validated by experts in the field of online food businesses. The questionnaire was validated by the following experts: A Food Stylist for Commercials and Digital advertisements and owner of a bake shop, an Owner and Pastry Chef of her own bread and pastry shop, and a Junior Sous Chef at Solaire Resort \& Casino. The reliability of the instrument was tested using Cronbach-alpha at .883 . The questionnaire will help the researchers in discovering the satisfaction of the guest towards the price, quality, service and other information needed for the completion of this study.

Data Gathering Procedure - The researchers wrote a letter for the three small online food businesses requesting for their data for the study that this study aims to benefit them and the customer using e-mail. After that, the researchers submitted their questionnaire to the expert to get the validity of the survey. After that, the researchers pilot tested the questionnaire where in the respondents are the customers of the three small online food businesses. Then, the data from the pilot testing went under reliability testing. After that, the certificates of validation and reliability was submitted to the research coordinator for verification. After the verification of the certificates, that was the time the researchers are going to start gathering the data and start making interpretation, analysis, conclusion and recommendations in constructing a basis for the action plan in the small online food business.

Data Analysis - The data were collected, analyzed, tabulated and interpreted using the following techniques. For the treatment of data in the study conducted by the researchers about the customers' experience and satisfaction on the food quality and the price. Average weighted mean. The average weighted mean was used in this study to measure the mean of the variables on the level of satisfaction in terms of price, quality, and service. The standard deviation will be used in this study to measure the standard deviation on the level of satisfaction in terms of price, quality, and service.

\section{Result and Discussion}

\section{Table 1}

Level of satisfaction in terms of price

\begin{tabular}{|c|c|c|c|}
\hline Indicators & & Mean & Interpretation \\
\hline Price of the food product & & 3.73 & Highly Satisfied \\
\hline Pricing of listed food products in the menu & & 3.64 & Highly Satisfied \\
\hline Delivery price of the food product & & 3.59 & Satisfied \\
\hline Pricing of promos during pandemic & & 3.65 & Highly Satisfied \\
\hline Pricing of the food product during pandemic & & 3.64 & Highly Satisfied \\
\hline & Over-all & 3.65 & Highly Satisfied \\
\hline
\end{tabular}

Legend: 3.51-4.00 Highly Satisfied; 2.51-3.50 Satisfied; 1.51-2.50 Not Satisfied; 1.00-1.50 Not Highly Satisfied.

In terms of price of the food product, the respondents assessed both the Price Affordability and Price Fairness as Highly Satisfied. This is because the selected small online food businesses have been pricing their products fairly for their targeted market. This can also mean that pricing of the selected small online food businesses is both affordable and fair. However, the respondents are only satisfied with the pricing of its delivery. This means that the respondents would prefer a cheaper delivery pricing for their products. As discussed by van Liere and Shulman. (2018), affordability is an important factor affecting low-income consumer demand for a variety of basic health products, including fortified foods. Yet, a low or cheap price will not always lead to purchase, even for poor consumers. Absolute price concerns are weighed against the perceived quality of a fortified product and against the price of similar products. 
Table 2

Level of satisfaction in terms of quality

\begin{tabular}{|c|c|c|c|}
\hline Indicators & & Mean & Interpretation \\
\hline Actual appearance of the food product & & 3.73 & Highly Satisfied \\
\hline Overall presentation of the food product & & 3.77 & Highly Satisfied \\
\hline Scent or Aroma of the food product & & 3.79 & Highly Satisfied \\
\hline Combination of scent and taste of the food product & & 3.79 & Highly Satisfied \\
\hline After taste of the food product & & 3.83 & Highly Satisfied \\
\hline & Over-all & 3.78 & Highly Satisfied \\
\hline
\end{tabular}

Legend: 3.51-4.00 Highly Satisfied; 2.51-3.50 Satisfied; 1.51-2.50 Not Satisfied; 1.00-1.50 Not Highly Satisfied.

In terms of the actual appearance of the food product, the respondents assessed the Appearance as Highly Satisfied. This is because the small online food businesses have been producing their products to its best form. Which covers the overall appearance, odor, and taste. This can also mean that quality of the selected small online food businesses has met all the aforementioned qualities which are Appearance, Odor, and Taste. While the sense of smell is involved in the anticipation of eating, as well as part of flavor perception during consumption, the sense of taste, by nature, is only in effect while food is ingested. Taste is primarily a nutrient sensing system (Boesveldt \& Graaf, 2017). As discussed by Maina (2018) Food aroma forms a crucial sensory signal and a fundamental component of flavor perception and thus it shapes the way people experience taste and texture.

Table 3

Level of satisfaction in terms of service

\begin{tabular}{lcc}
\hline \multicolumn{1}{c}{ Indicators } & Mean & Interpretation \\
\hline Products offered by the small online food business & 3.73 & Highly Satisfied \\
Convenience in which it does not cause complications & 3.72 & Highly Satisfied \\
Location of the small online food business & 3.67 & Highly Satisfied \\
Secureness of the packaging of the food product & 3.71 & Highly Satisfied \\
Overall freshness of the food product & 3.77 & Highly Satisfied \\
Over-all & 3.72 & Highly Satisfied \\
\hline Legend: $3.51-4.00$ Highly Satisfied; $2.51-3.50$ Satisfied; $1.51-2.50$ Not Satisfied; $1.00-1.50$ Not Highly Satisfied.
\end{tabular}

In terms of the products offered by the small online food business, the respondents assessed the Convenience as Highly Satisfied. This is because the small online food businesses have been very careful on choosing the right products for its market while also making sure that their products are not being compromised to bacteria's or any hazardous chemicals that may affect the food quality. They do this by using a well secured packaging to make sure no other chemicals may enter as well as to keep the food product intact to avoid unnecessary damages. This means that service of the selected small online food businesses has met all the aforementioned qualities which are Convenience and Food Safety Packaging.

As discussed by Kour et al. (2013), the principal function of packaging is protection and preservation from external contamination. This function involves: retarding deterioration; extending shelf life; and maintaining the quality and safety of packaged food. Packaging protects food from environmental influences such as heat, light, the presence or absence of moisture, oxygen, pressure, enzymes, spurious odors, microorganisms, insects, dirt and dust particles, gaseous emissions, etc. Secondary functions of increasing importance include traceability, tamper indication, and portion control. Food delivery in the Philippines is considered a major alternative to dining out and preparing meals at home for families who want a respite from home-cooked meals and cannot endure the inconveniences of dining out (Tomacruz \& Flor, 2018).

Table 4 shows that the most common problems the customers encountered is the delivery fee. The most common problem for the respondents is the delivery fee for the food product. This however, depends on the pricing the courier demands. The owner of the small online food business does not have the right to change or alter the price of the delivery the courier demands. The delivery fee would highly depend on the courier of the application the seller and the customer agreed upon. Second problem is the delivery time it takes. Just like the 
Velasco, J. K. D., Tatoy, A. A., Dela Cruz, C. L., \& Monzon-Po, S.

first problem it heavily depends on the courier not the seller. Because it is beyond the seller's action to demand a high-speed delivery to the courier. Third problem is the quality of the food getting ruined by the courier. The container can be put in a well-maintained packaging to avoid the quality being ruined but then again it would also depend on how the courier takes care of it. Lastly, the owner or seller of the small online food business is late to reply. A lot of factors can affect the tardiness of the owner but assuming that both the owner and customer has good internet connection this would fall on the mistake of the owner for not following the assigned hours to accept or entertain customers.

\section{Table 4}

Frequency distribution of problems encountered by customers

\begin{tabular}{lc}
\hline \multicolumn{1}{c}{ Problems } & Frequency (f) \\
\hline Delivery fee & 7 \\
Delivery time & 4 \\
Quality of food product/s getting ruined when being delivered. & 4 \\
Sometimes seller is late to reply & 2 \\
No delivery available only for pickup & 1 \\
Sometimes it is hard to order online & 1 \\
Sometimes products are not available & 1 \\
Wrong order received & 1 \\
\hline
\end{tabular}

Legend: 3.51-4.00 Highly Satisfied; 2.51-3.50 Satisfied; 1.51-2.50 Not Satisfied; 1.00-1.50 Not Highly Satisfied.

\section{Table 5}

Frequency distribution of recommendation given by the customers

\begin{tabular}{lc}
\hline \multicolumn{1}{c}{ Recommendations } & Frequency (f) \\
\hline More products and flavor variation & 7 \\
Promos or discount on food products or delivery & 6 \\
Free delivery & 3 \\
Punctual or early replies & 3 \\
To have your own delivery courier & 3 \\
Appealing packaging and presentation & 2 \\
Cheaper food products & 2 \\
More advertisements on your social media page & 2 \\
Always serve fresh cooked food products. & 1 \\
Make the packaging more secured and sealed & 1 \\
Menu of products should be posted & 1 \\
More payment options & 1 \\
Reusable packaging & 1 \\
Use more ingredients on food products & 1 \\
\hline Legend: 3.51-4.00 Highly Satisfied; $2.51-3.50$ Satisfied; $1.51-2.50$ Not Satisfied; 1.00-1.50 Not Highly Satisfied.
\end{tabular}

Legend: 3.51-4.00 Highly Satisfied; 2.51-3.50 Satisfied; 1.51-2.50 Not Satisfied; 1.00-1.50 Not Highly Satisfied.

Table 5 shows the ranking of suggestions given by the customers to further improve these selected small online food businesses. The most common suggestion given by the customers is add more products and flavor variations on their menu.

The most suggested option the customers would want on these selected small online food businesses is to add more products and flavor variation. This means that customers would really like it if there are more options available on their menu. And this will help and also attract customers to order different products and flavors. Second most suggested option is to add promos on their products and also discounts on their delivery fee. This means that customers are willing to purchase products from their small online food business if they would give out promos and also discounts on their delivery fee. This will help attract customers into availing their promos to not only lessen the cost but also attract awareness to other potential customers. Third suggested option is to make the delivery fee free. This means that customers would really prefer it if the delivery fee of their purchased food product is free. This will help lessen the total cost of the food product the customer ordered which in turn will also attract potential customers. 
Fourth suggested option is the punctuality or consistent replies. This means that customers would really prefer if the owner would consistently entertain and update any information about the customers' inquiries. This will make the overall experience of the customer better from ordering of the food product to updates about their purchased product. Fifth suggested option is for the small online food business to have a designated courier. This means that customers would really prefer if the small online food business will have its own designated delivery courier. Not only would it lessen the cost of the delivery but it will also monitor the quality of the food product. Sixth suggested option is to make the packaging and presentation of the food product more appealing. This means that the customers would really like if the overall appearance of the product is appealing. This will also help boost the small online food business' advertising of their product and will attract potential customers. Seventh suggested option is to make food products cheaper. This means that customers would really like the food products to be cheaper. This will also help lessen the expenses of the customer but it will be highly dependent on the financial status of the small online food business.

Eighth suggested option is to add more advertisements on the small online food business' social media page. This means that customers will prefer it if there are more sample photos of the food products being offered. This will help customers to see sample photos of the products being offered which in turn will also attract them to its appealing appearance. Ninth suggested option is to always serve their products fresh. This means that the freshness of the food product would affect its overall quality or expected quality. Freshness of the product can be preserved with the use of well-designed containers or packaging so that the overall quality will not be ruined. Tenth suggested option is to make the packaging more secured and sealed. This means that customers would prefer if the packaging of the food product is well secured and sealed to avoid contamination.

Using well-constructed packaging is highly required to avoid contamination and also to preserve freshness of the food product. Eleventh suggested option is to let the owners of the small online food businesses to post their menu on their social media page. This means that the customers would really like it if the menu is posted so that they could scan the menu. Posting of the menu of food products being offered will be convenient for the customers so that they would know the products being offered and their respective prices. Twelfth suggested option is to add more payment options. This means that there are customers who would prefer a different type of payment option on their transaction. This will help customers in ordering food products at ease without having to use payment options that are unfamiliar for them. Thirteenth suggested option is to use reusable packaging. This means that customers would like it if the packaging is reusable. This will help customers and also the owner into using reusable packaging to help lessen the costing. Lastly, the suggested option is to use more ingredients on food products. This means that the customers would prefer it if the food product would have additional ingredients to add a certain flavor to the food product. Although this will add cost but it will also improve the quality of the food product.

\section{Table 6}

Proposed action plan for the improvement of small online food businesses

\begin{tabular}{|c|c|c|}
\hline Recommendation & Rationale and Objectives & Strategy \\
\hline $\begin{array}{l}\text { Price Affordability - The researchers } \\
\text { recommend that the small online food } \\
\text { business make the price of both the } \\
\text { food product and delivery affordable. } \\
\text { By re-costing their offered products. } \\
\text { The costing should heavily depend on } \\
\text { their target market. So that it would fit } \\
\text { the right costing for the right market. } \\
\text { Or by also including certain promos } \\
\text { and discounts to further attract } \\
\text { potential customers. }\end{array}$ & $\begin{array}{l}\text { As part of the data gathered about problems } \\
\text { and suggestions the objectives of Price } \\
\text { Affordability are to: } \\
\text { To ensure the products and services to be } \\
\text { accessible to any customer class as it will } \\
\text { heavily affect the product's affordability. } \\
\text { To also ensure that the products and services } \\
\text { are well computed by the owner and not based } \\
\text { on their beliefs. This will help the owner cost } \\
\text { their products right. }\end{array}$ & $\begin{array}{l}\text { Strategy: } \\
\text { Determine your target market by doing a } \\
\text { Market Research Survey. } \\
\text { Re-cost current products based on its } \\
\text { target market. } \\
\text { Re-cost the new/current products based on } \\
\text { its target market and if it will fit your } \\
\text { desired promotion. } \\
\text { Proceed on selling if it meets every } \\
\text { requirement. }\end{array}$ \\
\hline $\begin{array}{l}\text { Price Fairness - The researchers } \\
\text { recommend that the businesses would } \\
\text { contact new suppliers to adjust the }\end{array}$ & $\begin{array}{l}\text { As part of the data gathered about problems } \\
\text { and suggestions the objective of Price Fairness } \\
\text { is to: }\end{array}$ & $\begin{array}{l}\text { Strategy: } \\
\text { If your costing is over your budget you } \\
\text { might as well look for another supplier. }\end{array}$ \\
\hline
\end{tabular}


price due to the pandemic. After sourcing and contacting their new supplier they should re-cost it again. After the pandemic the researchers also recommend to re-cost their products and adjust their price based on their target market.

Appearance - The researchers recommend that the small online food businesses should sell their product based on the appearance of the photo's they posted on their social media page/s. So that the customers will not be comparing the actual product and the photos posted in a negative way. Proper food handling should be monitored to prevent the overall appearance of the product.

Odor - The researchers recommend that the small online food businesses should add in appropriate and compatible, while also edible, fragrances or spices as garnish to add more aroma to the products. Carefully choose additional ingredients as it will heavily affect the finish product.
To boost the small online food business' relationship towards the industry. By sourcing new supplier, the objective is to lessen the cost as much as possible so that the pricing of the overall product is both fair and affordable.

As part of the data gathered about problems and suggestions the objectives of Appearance are to:

To attract customers based on product photos. And to follow proper food handling so that it will not ruin its overall quality.

To coordinate well with their designated courier so that the food product will be well maintained.

As part of the data gathered about problems and suggestions the objective of Odor is to:

To improve the overall aroma of the food product. While also boosting its quality and keeping inside the budget.

Once you have determined your new supplier or new costing proceed on selling your products.

Strategy:

1. create an appetizing photo:

Use your environment to create scenic photos based on the products theme.

Use your specialty glassware and utensils.

Zoom in your photo to show the inside or consistency of the final product.

Clean the area. Never forget to clean its surroundings so that it won't give a dirty impression.

\section{Strategy:}

Research about your food product.

List down possible alternatives or substitutes which improves the products aroma.

Source the desired ingredients. And Re-cost it

Try it.

Proceed on selling your product.

As part of the data gathered about problems and suggestions the objectives of Taste are to:

Taste - The researchers recommen that the small online food businesses pilot test their products from professionals or people who are experienced on the field of culinary. Letting your selected professional pilot test your products will help you on how to improved it and what should be avoided. Cooperate well with your selected professional as these people are already aware on what to add and what to remove so that your product will not go overboard on its expenses or it will not lack the desired taste.

Convenience - The researchers would like to recommend that the small online business should have a wide variety of products. In order to lessen the cost of adding new products it is highly recommended for the small online food business to use existing ingredients on creating a new product. The punctuality of the owner or the addition of a bot will not bore the customers as they browse the small online food business' menu. And lastly, to have a designated courier. Having a designated courier will lessen the cost of delivery and also to monitor the progress of the courier.

Food Safety Packaging - The researcher would like to recommend the small online food business to coordinate well with the professional who will pilot test their products. The professional will carefully recommend the appropriate and well secured packaging for their food products. Because these professionals will know
As part of the data gathered about problems and suggestions the objectives of Convenience are to:

To maximize the usage of ingredients and to introduced additional variety of products while keeping inside the budget.

To improve the alertness of the small online food business. Either by hiring an employee to handle customer inquiries or by adding a bot to entertain pending customers.

And lastly, to lessen the delivery cost by hiring a designated courier while also keeping track of the courier to inform your customer.

As part of the data gathered about problems and suggestions the objective of Price Affordability is to:

To improve the packaging of the food product. Packaging of the food product will heavily affect the quality of food based on its cross-contamination and its spoilage.
Strategy:

Source professionals in the industry through digital marketing

Cooperate well with your professional.

Show any evidences such as surveys to your professional. This will help both of you to brainstorm on how to improve your product.

Continue cooperating well with your professional to further improve your product and also for you to learn more about how to sell and make food products safely without losing your investments.

\section{Strategy 1:}

Research on other food dishes that consist of your existing ingredients.

List every possible dish.

Prepare a Market Research Survey which consists these products to narrow down what do the customers really want.

Once you determined the desired product. Try it.

Consult with your professional to know what to add and what to remove to prevent over spending.

Prepare the product for introduction selling.

\section{Strategy:}

Research about food packages regarding your food product. There are a lot of types of food packaging and it will depend on what kind of food product are you selling. You can also try to consult on your professional on the best type of food packaging regarding your food product.

To keep things interesting try to decorate 


\section{Conclusion}

The following presents the specific conclusions of the study: the respondents are highly satisfied with the pricing of the selected Small Online Food Businesses. This is because the Small Online Food Businesses has been pricing their products fairly for their targeted market. This can also mean that pricing of the selected Small Online Food Businesses is both affordable and fair. However, the respondents are only satisfied with the pricing of its delivery. This means that the respondents would prefer a cheaper delivery pricing for their products. The respondents are highly satisfied with the quality of the selected Small Online Food Businesses. This is because the Small Online Food Businesses has been producing their products to its best form. Which covers the overall appearance, odor, and taste. This can also mean that quality of the selected Small Online Food Businesses has met all the aforementioned qualities which are Appearance, Odor, and Taste. Service, the respondents are highly satisfied with the service of the selected Small Online Food Businesses. This is because the Small Online Food Businesses has been very careful on choosing the right products for its market while also making sure that their products are not being compromised to bacteria's or any hazardous chemicals that may affect the food quality. They do this by using a well secured packaging to make sure no other chemicals may enter as well as to keep the food product intact to avoid unnecessary damages. This means that service of the selected Small Online Food Businesses has met all the aforementioned qualities which are Convenience and Food Safety Packaging.

Price and Months of Operation revealed a very weak negative relationship due to the high number of satisfied customers. The reason why there is no correlation between Price and Months of Operation is that regardless of how long the business has been operating the satisfaction based on price would heavily depend on the business' pricing strategy. Quality and Months of Operation revealed a very weak negative relationship due to the high number of satisfied customers. The reason why there is no correlation between Quality and Months of Operation is that regardless of how long the business has been operating the satisfaction based on quality would heavily depend on the business' food quality. Service and Months of Operation revealed a very weak negative relationship due to the high number of satisfied customers. The reason why there is no correlation between Service and Months of Operation is that regardless of how long the business has been operating the satisfaction based on service would heavily depend on the business' performance towards its customers.

The most common problem for the respondents is the delivery fee for the food product. This however, depends on the pricing the courier demands. The owner of the small online food business does not have the right to change or alter the price of the delivery the courier demands. The delivery fee would highly depend on the courier of the application the seller and the customer agreed upon. Second problem is the delivery time it takes. Just like the first problem it heavily depends on the courier not the seller. Because it is beyond the seller's action to demand a high-speed delivery to the courier. Third problem is the quality of the food getting ruined by the courier. The container can be put in a well-maintained packaging to avoid the quality being ruined but then again it would also depend on how the courier takes care of it. Lastly, the owner or seller of the small online food business is late to reply. A lot of factors can affect the tardiness of the owner but assuming that both the owner and customer has good internet connection this would fall on the mistake of the owner for not following the assigned hours to accept or entertain customers.

\subsection{Recommendations}

The following recommendations are offered for the academic and small online food businesses for the researchers who plan to do a related research or improvement to this study: The researchers recommend that the small online food business make the price of both the food product and delivery affordable. By re-costing their offered products. The costing should heavily depend on their target market. So that it would fit the right costing 
for the right market. Or by also including certain promos and discounts to further attract potential customers. The businesses may contact new suppliers to adjust the price due to the pandemic. After sourcing and contacting their new supplier they should re-cost it again. After the pandemic the researchers also recommend to re-cost their products and adjust their price based on their target market. Moreover, it is recommended that the small online food businesses may sell their product based on the appearance of the photo's they posted on their social media page/s. So that the customers will not be comparing the actual product and the photos posted in a negative way.

Proper food handling should be monitored to prevent the overall appearance of the product. And to coordinate well with their designated courier to prevent the product from being ruined. Small online food businesses pilot tests their products from professionals or people who are experienced on the field of culinary. Letting your selected professional pilot test your products will help you on how to improved it and what should be avoided. Cooperate well with your selected professional as these people are already aware on what to add and what to remove so that your product will not go overboard on its expenses or it will not lack the desired taste. Lastly, the researchers would like to recommend that the small online business should have a wide variety of products. In order to lessen the cost of adding new products it is highly recommended for the small online food business to use existing ingredients on creating a new product. Example: A peach pie can be made into a peach tart. Both using the same ingredients while being different in terms of type of dessert. This will help the small online food business to widen its products variation while also keeping its cost inside the budget. While it is recommended to widen the variety of products it is also recommended for the small online food business to do a Market Research Survey. Asking its recent or potential customers on what they should see next on their product lineup will help the small online food business get an idea on what the customers want next and what should be removed from their existing products. They should be alert at all times when conversing with their customers or by adding a bot to entertain pending customers. The punctuality of the owner or the addition of a bot will not bore the customers as they browse the small online food business' menu. And lastly, to have a designated courier. Having a designated courier will lessen the cost of delivery and also to monitor the progress of the courier.

\section{References}

Boesveldt, S., \& de Graaf, K. (2017). The differential role of smell and taste for eating behavior. Perception, 46(3-4), 307-319. https://doi.org/10.1177/0301006616685576

Hanaysha, J. (2016). Testing the effects of food quality, price fairness, and physical environment on customer satisfaction in fast food restaurant industry. Journal of Asian Business Strategy, 6(2), 31-40. https://doi.org/10.18488/journal.1006/2016.6.2/1006.2.31.40

Kannan, R. (2017). The impact of food quality on customer satisfaction and behavioural intentions: A study on Madurai restaurant. Innovative Journal of Business and Management, 6(3), 34-37.

Kour, H., Wani, N. A. T., Malik, A., Kaul, R., Chauhan, H., Gupta, P., ... \& Singh, J. (2013). Advances in food packaging-a review. Stewart Postharvest Review, 9(4), 1-7. https://doi.org/10.2212/spr.2013.4.7

Maina, J. W. (2018). Analysis of the factors that determine food acceptability. The Pharma Innovation, 7(5, Part D), 253.

Sanchez, M. J. (2020). Internet user penetration in the Philippines from 2017 to 2019 with a forecast until 2025. Retrieved from https://www.statista.com/statistics/975072/internet-penetration-rate-in-the-philippines/

Tomacruz, M. D. G., \& Flor, N. T. (2018). Family perception and their buying behavior for home-delivered food. International Journal of Tourism Sciences, 18(4), 237-246. https://doi.org/10.1080/15980634.2018.1551308

van Liere, M. J., \& Shulman, S. (2018). Creating consumer demand and driving appropriate utilization of fortified foods. In Food Fortification in a Globalized World, 101-112. https://doi.org/10.1016/B978-0-12-802861-2.00010-9 